\title{
Manuscritos de Medicina y Farmacia rioplatenses: un estudio comparativo entre la Materia Médica Misionera y el o Libro de Cirugía
}

Manuscritos de Medicina e Farmácia rioplatenses: um estudo comparativo entre a Materia Médica Misionera e o Libro de Cirugía Manuscripts of Medicine and Pharmacy from the Plata River: a comparative study between Materia Médica Misionera and the Libro de Cirugía

Eliane Cristina Deckmann Fleck and Maico Biehl

\section{OpenEdition}

\section{Journals}

Electronic version

URL: http://journals.openedition.org/corpusarchivos/3633

DOI: $10.4000 /$ corpusarchivos.3633

ISSN: 1853-8037

Publisher

Diego Escolar

\section{Electronic reference}

Eliane Cristina Deckmann Fleck y Maico Biehl, « Manuscritos de Medicina y Farmacia rioplatenses: un estudio comparativo entre la Materia Médica Misionera y el o Libro de Cirugía », Corpus [En línea], Vol. 10, No. 1 | 2020, Publicado el 28 junio 2020, consultado el 02 julio 2020. URL : http:// journals.openedition.org/corpusarchivos/3633; DOI : https://doi.org/10.4000/corpusarchivos.3633

This text was automatically generated on 2 July 2020. 


\section{Manuscritos de Medicina y Farmacia rioplatenses: un estudio comparativo entre la Materia Médica Misionera y el o Libro de Cirugía}

Manuscritos de Medicina e Farmácia rioplatenses: um estudo comparativo entre a Materia Médica Misionera e o Libro de Cirugía

Manuscripts of Medicine and Pharmacy from the Plata River: a comparative study between Materia Médica Misionera and the Libro de Cirugía

Eliane Cristina Deckmann Fleck and Maico Biehl

\section{EDITOR'S NOTE}

Fecha de recepción del original: 12/10/2019

Fecha de aceptación para publicación: 20/04/2020

\section{Introdução}

Muitos dos manuscritos de etnobotânica e medicina relacionados nos catálogos de bibliotecas e arquivos europeus e latino-americanos não foram ainda publicados ou mais detidamente analisados pelos pesquisadores, sobretudo, em termos de sua relevância para a identificação e discussão das evidências de apropriação e circulação de conhecimentos clássicos de Medicina e Farmácia e de saberes nativos. Dentre esses manuscritos, destacam-se a Materia Médica Misionera, de 1710, e o Libro de Cirugía, de 1725 , que analisamos no presente artigo. 
2 Materia Médica possui 458 páginas, 148 ilustrações de plantas e um frontispício com a imagem de Nossa Senhora das Dores, padroeira dos enfermos. Circulando em versões manuscritas pela América platina, a obra só veio a ser editada e publicada em 1888, por iniciativa de Ricardo Trelles, na Revista Patriótica Del Pasado Argentino. Outras edições são a da Biblioteca Nacional de Buenos Aires, de 1945, e a de Carmen Martín Martín, de 1995.

3 A segunda obra analisada intitula-se Libro de Cirugía. Trasladado de autores graves y doctos para alívio de los enfermos. Escrito en estas Doctrinas de la Compañía de Jesús, año de 1725, e uma de suas versões manuscritas encontra-se na Biblioteca do Convento da Ordem Franciscana da cidade de Catamarca, Argentina. ${ }^{1}$ Contando com 660 páginas, algumas das quais ilustradas com desenhos de instrumentos cirúrgicos e tabelas com diversas informações, o Libro de Cirugía permanece ainda inédito. Pequenos excertos e ilustrações da obra foram publicados por Garzón Maceda (1916) e, posteriormente, também por Guillermo Furlong (1947).

4 Contrastando com as limitadas e parciais informações que dispomos sobre o manuscrito Libro de Cirugía, Materia Médica Misionera já mereceu inúmeros estudos. ${ }^{2}$ Se, para a segunda, a historiografia afirma que seu autor foi o irmão jesuíta Pedro Montenegro (Furlong, 1947), ${ }^{3}$ para o primeiro não existe consenso quanto à autoria atribuída por Garzón Maceda (1916) ${ }^{4}$ e Furlong (1947).

5 O irmão jesuíta Pedro Montenegro nasceu em 14 de maio de 1663, na cidade de Santa Marina, na região da Galícia, na Espanha. Em 1679, com dezesseis anos de idade, foi admitido como aprendiz no Hospital Geral de Madrid e, desde então, sua trajetória sempre esteve associada às artes de curar. Seu ingresso na Companhia de Jesus se deu em 1691, quando já se encontrava na América. Enviado à cidade de Córdoba, atuou como boticário até 1703, quando passou a missionar na redução de Apóstoles e, entre 1705 e 1724, nas reduções do Paraná. No intervalo dos anos de 1703 a 1705, deixou as reduções para atuar como enfermeiro e cirurgião junto às milícias indígenas enviadas à Colônia de Sacramento, ${ }^{5}$ território em disputa entre as Coroas de Espanha e Portugal. Faleceu em 20 de fevereiro de 1728, aos 65 anos de idade, na redução de Mártires.

6 Nos próximos tópicos, contemplamos os resultados de um exercício comparativo ${ }^{6}$ entre as duas obras, que considerou os indícios de intertextualidade, ${ }^{7}$ bem como as aproximações e distinções identificáveis entre suas estruturas e estilos narrativos, ${ }^{8} \mathrm{a}$ fim de subsidiar o questionamento da visão historiográfica mais consagrada e que atribui ao irmão jesuíta a escrita dessas duas obras.

\section{Sobre distinções evidentes e aproximações possíveis}

7 Se estudos recentes realizados sobre a Materia Médica apontam que 92,3\% dos dados nela apresentados se referem às virtudes medicinais de cento e quarenta plantas (Scarpa y Anconatani, 2019), ${ }^{9}$ a análise que realizamos do manuscrito Libro de Cirugía revelou que ele se detém na descrição de partes específicas do corpo, nos modos de preparo de medicamentos e nos procedimentos terapêuticos, vinculando-os a práticas cirúrgicas.

8 Mas as diferenças entre as obras se fazem também notar na forma como foram organizadas. Apesar de ambas apresentarem um Prólogo, no qual o leitor é informado sobre os cuidados que deveriam ser observados, por exemplo, na coleta de plantas e no 
preparo das receitas, os títulos dos capítulos das duas obras reforçam que a Materia Médica foi proposta para ser utilizada como manual de botânica médica e que o Libro de Cirugía estava direcionado para a prática médico-cirúrgica. ${ }^{10}$ Por outro lado, ambos os autores tinham uma visão do conjunto de suas obras, como podemos depreender da passagem abaixo, extraída da Materia Médica:

(...) y en fin, misto el Guayacán con la Aristoloquia rotunda no hay mal frances que no cure, y todas las enfermedades de reumas frias, como diré en el capítulo del palo santo del Guaycurú aromatico, haciendo bebidas magistrales, segun la nesecidad y sujetos, ó complicacion de morbos (Montenegro, 1945, p. 79, grifos nossos). ${ }^{11}$

O mesmo pode ser percebido no Libro de Cirugía, pois, não raro, seu autor-compilador ${ }^{12}$ preocupa-se em informar ao potencial leitor onde poderia encontrar informações correlatas na obra, como por exemplo, nessa passagem, na qual, ao abordar a fiebre putrida (tifo), avisa que "El regimiento de las fiebres efimera, y etica se pondrà en los capitulos de sus propias curaciones" (Libro de Cirugía, 1725, p. 342).

11 Os autores se aproximam também em sua compreensão de que o restabelecimento dos enfermos não se dava exclusivamente pelas virtudes medicinais das plantas e da aplicação adequada de receitas e tratamentos, mas pela ação divina em uma região que se caracterizava pela escassez de médicos e recursos e pela alta incidência de doenças. Na Materia Médica, o autor deixa essa percepção muito evidente:

El Todo Poderoso, y Sempiterno Dios, que crió los hombres y animales en la tierra, crió las plantas, árboles y yerbas, con no menor admiración del hombre racional, que con razon y discurso, y por la experiencia rastrea sus virtudes, para bien y provecho del género humano, pues en la abundancia diversidad de figuras, sabores, y olores de sus ojas, frutos, y troncos recrean, sustentan y curan al hombre jen este Valle de lágrimas, y destierro miserable!! Para que por ella vengamos en conocimiento de nuestro Criador, y bien Sempiterno (Montenegro, 1945, p. 257).

13 Para o irmão Montenegro, a capacidade de identificar moléstias, de preparar remédios e de amenizar a dor e recuperar enfermos deviam ser percebidos como atos de compaixão e de atendimento aos desígnios de Deus. A mesma percepção pode ser encontrada no Libro de Cirugía, reforçando a interpretação de que o atendimento dos doentes era orientado pela prática da caridade, como na passagem em que seu autor afirma:

Daras pues quando tubieres señales para esto, la sena, el Xaraue de Mosqueta, los tamarindos, e la caña fistola, y no hauiendo otra Purga, daras el mechoacan, o lo dispondras con la leche tresna que es la ordinaria Purga de los Pobres Yndios (Libro de Cirugía, 1725, p. 342). ${ }^{13}$

15 Apesar de os saberes e as práticas curativas (propriedades medicinais de determinadas plantas e de certos compostos químicos) ${ }^{14}$ veiculados nas duas obras serem amplamente difundidos na região platina, a partir da circulação de cópias dos receituários e de sua reprodução através da tradição oral, ${ }^{15}$ não podemos deixar de registrar a constatação de que muitas das plantas descritas na Materia Médica estão também presentes em receitas do Libro de Cirugía, mesmo que de forma menos aprofundada. À verbena, por exemplo, ${ }^{16}$ são dedicadas várias páginas da Materia Médica:

Tiene la Verbena sus tallos cuadrados encima de los cuales hace sus semillas en unas espigas á modo de canelones de disciplinas delgadas, en las cuales bá poco á poco echando su flor, conforme ellos bán creciendo, como aquellas del llanten, las cuales son moradas y muy amargas: la semilla pequeña, y parduzca ó lara. Llamanla 
yerba sagrada palomera, (Peristereom en Griego,) por lo mucho que las palomas se regocijan y alegran con ella, y procuran revolearse, y habitar á donde ella nace. (...) La Verbena, ó yerba sagrada comun, son dos, macho y hembra, las cuales posehen una misma virtud; cocidas en aceite, ó fritas sus ojas despues de machacadas, y úntandose por espacio de tres dias la cabeza con él tibio, quita todos los antiguos dolores de cabeza, y restaura los cabellos perdidos, y establece los caducos y que se quieren caer, cuando los tales dolores proceden de causa fria.- Sus ojas y raiz cocidas con vino bebidas, y aplicadas á forma de emplasto atajan las llagas que bán cundiendo, y el fuego de San Anton. Dase á beber contra las fiebres tercianas el tercer nudo con todas sus ojas, comenzando á contar de la raiz: y contra las cuartanas el cuarto, y esto hace con mayor eficacia cojiendola el primer dia de Luna, como lo muestra la experiencia. Tomando su cocimiento en ayunas con unas gotas de vinagre de buen vino, y una onza de miel, ó azucar, y por espacio de tiempo úsada es admirable remedio contra las fiebres malignas, y putridas: - contra la Itericia (Montenegro, 1945, p. 211-213).

Por sua vez, no Libro de Cirugía, a verbena é apresentada em alguns parágrafos, mantendo-se as informações principais, como sua morfologia e suas qualidades medicinais contra febres, dores de cabeça, queda capilar e ergotismo: ${ }^{17}$

La verbena nase en lugares aquosos, las Palomas se guelgan a donde hella se halla de frequentar, crese de la altura de un palmo, y algunas veses mayor, sus ojas nasen del mismo tallo, y son endidas,y blanquesinas, por la mayor parte consta de un solo tallo, y de una sola raiz, los ramos son quadrados; sus ojas maxadas, y aplicadas con aseyte rosado, o con injundia de Puerco fresca, quitan el dolor de la Madre; aplicandose con vinagre atajan el fluxo de San Anton, y reprimen las llagas llenas de corruptela; mescladas con miel sueldan las eridas resientes, y las antiguas en cora. Su cosimiento vebido es bueno contra todas las indispocisiones del vientre, desopila Ygado, Pulmones, y los riñones. Dice el doctor Laguna es la verbena estiptica, desecatiba, y con calor notable; eruida con aseyte, y aplicada resuelbe los antiquos dolores de cauesa procedentes de causas frias, y restablece los cavellos caducos, fortifica todos los dolores inferiores miembros, suelda las venas rotas, y despide por sudor los quajarones de sangre recogidos en algunas partes del cuerpo (Libro de Cirugía, 1725, p. 494).

Em ambas as obras encontramos evidências da aplicação de pressupostos da teoria hipocrático-galênica, que pressupunha que a saúde de um indivíduo resultava do equilíbrio - ou não - de quatro humores, a saber, o sangue, a bílis negra, a bílis amarela e a fleuma, presentes no corpo humano. Cada um destes humores teria qualidades, como quente, frio, seco e úmido, logo, os remédios aplicados deveriam considerar qual humor se encontrava em desequilíbrio e suas qualidades.

19 Em diversas passagens da Materia Médica, Montenegro deixa evidente a adoção dos pressupostos humoralistas, como por exemplo, ao dissertar sobre as propriedades da canafístula. ${ }^{18}$ Recorrendo a dois importantes autores, Mathiolo e Laguana, o irmão jesuíta afirma que:

20 Mathiolo dice ser [canafístula] remedio muy seguro en el principio de todas las enfermedades que provienen de calor, porque limpiando el estómago y vientre es más segura y acertada la sangria.

21 Laguna dice: clarifica la sangre, refrena el ardor de la colera, y purga ligeramente los humores colericos y flematicos, que andan bagando por el cuerpo, vientre y estómago (Montenegro, 1945, p. 74). 
autor-compilador do Libro de Cirugía também recorre aos princípios da teoría hipocrático-galênica para, por exemplo, destacar as virtudes do xarope de palo santo: “ Sirve principalmente para purgar los humores flematicos, frios, galicos, y contumaces, deostruye, y corta los crasos, y viscosos humores; pero si huviere fiebre intensa, se mezclará con cosas refrigerantes para administrarse" (Libro de Cirugía, 1725, p. 82).

Tanto Montenegro, quanto o autor-compilador do manuscrito dedicam várias linhas para ressaltar a necessidade de que os preparos descritos fossem executados com o maior respeito possível às medidas, à sequência de preparo, às formas corretas de armazenamento e à sua validade. Isto se observa notadamente no Libro de Cirugía, em especial no Dispensatório Medicinal, no qual encontramos o alerta de que o descumprimento desses cuidados incidia diretamente na eficácia do tratamento. Também a coleta das plantas deveria observar as condições climáticas, o ciclo lunar e as estações do ano, bem como as fases de desenvolvimento das plantas. Na obra Materia Médica, tais advertências são feitas com base em doze pontos retirados das obras de Dioscórides e de Laguna. Veja-se, por exemplo, a sexta advertência:

yerbas que extienden ramos por tierra para guardarse para el año deben recojerse cuando están cargadas de flores, como es el Bledo menor, la acetosa mayor, el Poleo, el Hisopo, y agedrea, y otras á este modo. Las demas que crecen en alto se recojerán cuando estén llenas de sus cimientes, ántes que de sí mismas se caigan, y sus frutos ó semillas cuando estén sazonados ántes de caer á tierra: excepto los frutos de las cosas astringentes, que se deben recojer ántes de sazonar, como son la semilla de Arrayán, las baulautrias, las Guayabas, y otros á este modo (Montenegro, 1945, p. 12). ${ }^{19}$

No Libro de Cirugía, o autor-compilador refere as mesmas orientações descritas na Materia Médica, apontando para sua difusão e aplicação na região platina:

Los simples medicamentos, se deben recoger cuando su virtud está más entera, y fuerte, más es dificultoso determinar el tiempo, por causa de su diversa dureza: Las raíces son buenas en todo tiempo, aunque Dioscórides, dice, que en el Otoño. La planta entera ha de ser cogida en su mayor vigor, antes que tenga formado el fruto, ni la simiente. Las hojas han de ser cogidas antes de caerse, estando de buena madurez, porque entonces su zumo llegò a cierta especie de fermentación. Las simientes si han de coger secas: Las flores en su rigor: Los frutos maduros: Los Zumos se deben sacar cuando las plantas van creciendo, y que están en su maduro verdor (Libro de Cirugía, 1725, p. 21).

27 A menção à aplicação dos pressupostos de Dióscorides em ambas as obras, no entanto, não pode ser tomada como indicativo de que a Materia Médica e o Libro de Cirugía tenham tido o mesmo autor. Assim como as menções feitas às mesmas plantas e a procedimentos curativos similares não podem ser tidas como comprovação de que o irmão jesuíta Pedro Montenegro tenha sido o autor do tratado de botânica médica e, também, do de prática médico-cirúrgica. ${ }^{20}$

Tendo em vista as influências teóricas que os autores possam ter recebido, através da consulta a obras clássicas e contemporâneas, e ter evidenciado em suas obras, nós as analisamos com o propósito de identificar indícios de intertextualidade que poderiam conferir credibilidade aos seus escritos (Certeau, 2011). ${ }^{21} \mathrm{O}$ cotejo entre duas as obras revelou menções a sessenta e cinco autores no Libro de Cirugía e a trinta e quatro autores na Materia Médica, ${ }^{22}$ sendo que deste conjunto de autores, dez deles são mencionados em ambas as obras, a saber, Fr. Augustin Farfán, Cláudio Galeno, Riverio 
[Riveiro], Andrés Laguna, Mathiolo Senense, Juan Mésué, Madame Fouquet, Dioscórides, Avicena e Plinio. ${ }^{23}$

Constatamos, ainda, que o autor-compilador do Libro recorreu a trinta e cinco autores modernos, em especial, do século XVII, a cinco autores da Antiguidade, a cinco do período medieval e a vinte autores sobre os quais não encontramos maiores informações. Obviamente, o predomínio de referências a autores do Seiscentos não implica pensar em uma menor influência dos autores clássicos de medicina, farmácia e botânica no manuscrito de 1725 .

Para além das menções diretas feitas a autores em ambas as obras, observou-se a prática da compilação ou, então, de cópia de trechos longos extraídos de tratados clássicos e modernos. Se estudos já realizados da Materia Médica apontaram para a utilização de trechos e, notadamente, de ilustrações da obra de Guilherme Piso (Quintana, 1945), ${ }^{24}$ o mesmo pode ser observado no Libro de Cirugía, uma vez que seu autor transcreve quase que integralmente o "Tratado de Anatomia del Doctor Don Manuel de Porres" 25 e o "Tratado Brebe del modo de Sangrar por Diego Perez de Bustos, sangrador del Rey, Alcalde, y Examinador de los Barberos Flobotomianos", ${ }^{26}$ sendo que os títulos dessas obras são mantidos nos capítulos do Libro.

Observou-se, ainda, que algumas obras são mencionadas indiretamente, na medida em que o autor-compilador faz referência aos seus autores, como se pode constatar nessa passagem: "Felix Platero dice haver curado una llaga en el hondo de la boca, que havia comido la mitad dela campanilla, y con estos perfumes curo lo que no pudieron hacer los otros remedios. Vigier página 486" (Libro de Cirugía, 1725, pp. 243-244). ${ }^{27}$ Logo no início de sua obra, o autor-compilador menciona os autores que foram fundamentais para a escrita do Libro de Cirugía:

(...) todo lo contenido lo he sacado de autores clásicos y doctos que son para la medicina de las obras del doctor Gordino [sic], del Libro de la peste del doctor Luis Mercado, del Compendio de don Juan de la Torre, del médico caritativo, por el licenciado Félix Borbón, de "La llave de oro" del doctor Trapiella, del "Tesoro" de Juan Vigier, y del libro del doctor P. Fray Agustín Farfán, y de los experimentos del doctor Gerónimo Soriano. Para lo pertinente a cirugía me he valido de la obra del licenciado Dionisio Daza y la del Doctor Juan Calvo, de la cirugía de Antonio de la Cruz, de la del doctor Antonio de Robledo, de la del licenciado Porres y del Cirujano Caritativo (Libro de Cirugía, 1725, p. 9)..$^{28}$

Em relação ao Prólogo, cabe observar que, a despeito da menção aos clássicos, não predominam no Libro os autores da Antiguidade. Já no Prólogo ao Leitor da Materia Médica, constata-se a referência a "los autores modernos", apontando para a conciliação entre estes os clássicos:

hombres con particular inclinación al descubrimiento y averiguacion de las plantas (...) cual á un DiosCorides; un Mathiolo Senense, un Andres de Laguna, y otros varios (...) como Plinio, Huerta, Menardes, Pisón, Bonti, Sirena, Leon, y Bauthin, que son los que hasta hoy he podido leér sus obras (Montengero, 1945, pp. 5-6).

Contudo, nem só da leitura de obras de referência se valeram os autores das obras analisadas, como se pode observar nessa passagem extraída do Libro de Cirugía, na qual o autor-compilador disserta sobre as propriedades da cal dissolvida em água:

Puedo decir que aumentando, o disminuyendo la virtud de esta agua, es un remedio universal para llagas simples, y compuestas; y aseguro de corazón, que muy doctos, y experimentados cirujanos, me han confesado que no hay ungüento, ni emplastos que la igualen en la virtud, pues los unos, y los otros, impiden la exicacion [sic] por su untuosidad (Libro de Cirugía, 1725, p. 120, grifos nossos). 


\section{${ }^{29}$ destacando sua atuação como informantes:}

Por consejo del Hermano Joaquin curè a un sujeto en estas Doctrinas de enfermedad de piedra, y retención de orina con dịcha Yerua, la qual hise husar por 9 mañanas en aiunas una cucharada del Polbo de sus ojas cada resen un guebo blando, despues de hauerle hecho dos sangrias, y purgadolè, y le hiso tan buen provecho, que desde entonses no ha sentido piedra, ni embaraso en la orina, y han pasado 6 años, sintiendo antes de continuo grandes dolores.

El Hermano Enrique comunicandomè el año pasado la virtud que para curar de la piedra tiene dicha virga aurea sin sauer el caso referido, me contò otro semejante, que como por acaso le hauia pasado en Cordova [sic] con un secular el qual quedò tan aficionado a la Yerua que siempre la guardaua en su casa como asù unico remedio (Libro de Cirugía, 1725, pp. 307-308, grifos nossos).

Na Materia Médica, Montenegro também aponta para a importância da troca de informações, ao mencionar que seu contato com a planta "yerba de la víbora", ${ }^{30}$ descrita por suas propriedades antiofídicas, se deu em função do encontro que havia tido com o reitor do Colégio de Tucumán:

Esta yerba de la vivora de Tarija, tuve noticia de ella, y de su grande eficacia: estando en el Colegio de Cordoba, y pasando al de Tucumán, quiso mi fortuna, y la de otros muchos, que con ella he curado, el que la viese con todas sus partes, menos la flor, que la traia el Padre Rector, que al presente éra de aquel Colegio el P. Diego Ruiz, quien partió conmigo la tercia parte del ház que traia, y hallé ser amarga sin acervidad alguna, ántes si, un amargor grato al estómago, y muy confortativo al corazon y celebro (Montenegro, 1945, p. 377, grifos nossos).

Também nos ocupamos de identificar evidências de experimentação pessoal dos procedimentos indicados nas duas obras, para que pudéssemos, através delas, corroborar a visão historiográfica que atribui a mesma autoria à Materia Médica e ao Libro. Em algumas passagens, contudo, fica evidente que as indicações foram feitas com base na consulta a obras de referência:

Usase el mercurio vivo con los que padecen el dolor de hijada, que dicen miserere, dándoles por la boca dos, o tres libras, y en la misma cantidad sale por la usa mayor, y es mejor darlo en dosis grande que pequeña para que con el peso descienda presto, y por otras razones, que dice Castellon fol. 55, de chimica (Libro de Cirugía, 1725 , p. 51, grifos nossos).

Dentre as passagens que atestam que houve, não apenas a experimentação, mas também a utilização de plantas medicinais nativas, em substituição àquelas indicadas nas receitas que constavam nas obras de referência, destacamos as que seguem e que foram extraídas do Libro de Cirugía:

Este modo de hacer el xarave de mosqueta con el roció en lugar de agua lo trae Castellon fol. 139. Pero aqui por el poco alino que hay, no se puede recoger el rocio, $\mathrm{y}$ asì en falta Suya tomaremos la misma cantidad de agua natural clara, $\mathrm{y}$ en ella se haran las quatro infusiones, o más con el methodo que se ha dicho en el primer Capítulo de infusiones; luego tomadas seis libras de infusion pura, y libre de las heces, se le mezclaran quatro libras de azucar blanca para darle punto de xarave, lo qual se harà en vaso de Tierra sobre fuego blando (Libro de Cirugía, 1725, p. 83, grifos nossos).

En esta Tierra como no tengamos la rosa de Alexandria, que es principalmente de la que se hace mucho caudal para las infusiones solutivas, nos valemos de la rosa palida, que llaman mosqueta, la qual verdaderamente es admirable para purgar los humores, y quizas superior en virtud a la Alexandrina. La Rosa fina que dicen Castellana, aunque sea cordial, y confortativa del estómago, higado, y demás 
miembros, por ser más restrictiva que purgante, se usa poco hacer con ella xaraves solutivos (Libro de Cirugía, 1725, p. 86, grifos nossos). ${ }^{31}$

Las experiencias felicisimas, enseñan que este unguento es utilissimo para las almorranas, asi ciegas, como aviertas internas, y externas, inflamadas, y timidas, de qualquiera causa que provenga el dolor, aplicando este ungüento se mitiga, y ablanda, si el intento es refrigerar, se mezclara al aplicarlo con un poco de Leche de muger, o de Baca, o con Zumo de Berdolagas batiendolo para que se incorpore (Libro de Cirugía, 1725, p. 109, grifos nossos). ${ }^{32}$

Advierto que solo escrivo aqui aguas experimentadas con felicissimos sucesos para muchissimas enfermedades con particularidad para las cronicas, y reveldes podranlas tomar los pobres, sin faltar a su trabajo, el corte para fabricarlas es muy poco. (Libro de Cirugía, 1725, p. 115, grifos nossos). ${ }^{33}$

No quiero ocultar lo que la experiencia me ha enseñado, y es que esta agua cura prodigiosamente las quartanas, si se dan dos tazas en el principio del frio. Si estuvieres sin tener esta agua preparada, toma doce granos del vitriolo, remojaraslo espacio de doce horas en dos tazas de agua, y daraslas al enfermo en dicho tiempo (Libro de Cirugía, 1725, p. 117, grifos nossos). autor-compilador em relação à realidade de seu potencial público leitor, o que fica expresso na seguinte afirmação: "Pero como escrivo para los pobres enfermos de la Campaña, quiero proponer modo más facil, y sin gastos" (Libro de Cirugía, 1725, p. 120). Percebe-se, ainda, que o autor preocupou-se com a forma como foram dispostas as compilações e receitas: "Todo el Libro, aunque no está dispuesto con la buena orden, y aliño que yo quisiera por mi grande insuficencia; todavia se declara lo bastante, y mejor que otros manuscritos, que se hallan a cada paso (...)" (Libro de Cirugía, 1725, p. 12).

A experiência é igualmente valorizada e registrada por Montenegro (1945, p. 21), como se pode observar no Prólogo ao Leitor da obra, no qual ele afirma que "(...) puedo asegurar, que lo que aqui pongo es lo que yo he practicado con sumo cuidado (...)", e, ainda, na passagem em que ressalta que "por la experiencia rastrea sus virtudes, para bien y provecho del género humano" (Montenegro, 1945, p. 257).

Vale lembrar que compilar e escrever, considerando a melhor organização e estilo narrativo a fim de melhor atender a um determinado público leitor, constituem ações que revelam a preocupação de um autor com a "comunidade interpretativa", aquela que, segundo Chartier (1992, p. 216), compartilha "os mesmos estilos de leitura e as mesmas estratégias de interpretação". No caso das duas obras analisadas, é preciso, ainda, agregar, o conhecimento, por parte dos autores, da realidade vivenciada pelos indivíduos saudáveis e/ou enfermos para os quais a Materia Médica e o Libro de Cirugía se dirigiam.

\section{Sobre o contexto e o lugar de produção}

41 A adoção de uma perspectiva comparativa entre as duas obras põe em debate o lugar em que foram produzidas. Conforme Michel de Certeau (2011, p. 57), toda a escrita "É o produto de um lugar", cuja influência no discurso elaborado manifesta-se nos métodos empregados, nos interesses assumidos, nas questões propostas e na sua organização (Certeau, 2011). Ambos os manuscritos trazem em seus frontispícios a marca jesuítica, uma vez que os títulos Materia Médica Misionera e Libro de Cirugía médica transladada de autores graves y doctores para el alívio de los enfermos. Escrito en estas Doctrínas De la Compañía de Jesus remetem às reduções da Província Jesuítica do Paraguai. Mais do que 
evidenciar a instituição na qual seus autores se encontravam inseridos, os títulos apontam para o fato de que foram escritos em meio à rotina diária das reduções, aos desafios da missionação e ao meio natural em que elas se encontravam instaladas. ${ }^{34}$

Esse aspecto é, aliás, muito evidente na Materia Médica Misionera. Nela, a paisagem ${ }^{35}$ das reduções jesuíticas e os dilemas próprios de seu cotidiano são apresentados ao leitor. Em razão disso, ao descrever as plantas, Montenegro não se limita apenas a mencionar sua espécie, trazendo também informações sobre seu habitat, como se pode observar na descrição que faz do altocigo: ${ }^{36}$

El Yapacarií, que Mathiolo llama Pistacia, y en España llaman Altocigo, se hallan por estas Misiones muy de ordinario en tierras húmedas, en los bosques de bajíos, cerca de ríos ó arroyos: es árbol alto, y frondoso, mayormente cuando se halla en las partes dichas de tierra craza y pingüe; pero cuando se halla en tierra de serranías sobre piedra no crece tanto, á imitación de los demás arboles; pero es más amargo y agudo, y más eficaz en medicina (Montenegro, 1945, p. 304, grifos nossos). ${ }^{37}$

A referência aos elementos naturais, tais como arroios, rios, bosques e terras úmidas, não só coloca em relevo cenas próprias da paisagem da América platina, como tem a função de auxiliar na identificação de cada planta medicinal, dada a falta de um preciso sistema de classificação das espécies à época. ${ }^{38}$ Nesse sentido, não só a natureza ajudava a orientar a localização das plantas, mas, também, os elementos artificiais da paisagem, como o conjunto de edificações que formavam as reduções. Pode-se observar esses aspectos na descrição da Yerba Santa, ou Caá Curuzú̉ ${ }^{39} \mathrm{em}$ guarani, cujas propriedades, segundo o autor, combatem as enfermidades estomacais e intestinais e, "Hallase en cantidad por las partes dichas en las tierras de San Luis, San Lorenzo S. Miguel, San Juan, y San Angel, y en los Apostoles, Concepcion y S.n Carlos tal cual mata suya" (Montengero, 1945, p. 205 , grifos nossos). Na menção que o autor faz à planta canchalágua, ${ }^{40}$ ele faz referência ao conhecimento que os nativos tinham sobre a flora nativa existente no entorno das reduções:

El Capiî irópitá hallo usarlo los Indios para matar las lombrices del estómago y vientre, bebiendo su cocimiento, y por ayuda administrado (...) que el Indio llama Caané miri, con miel y sal y graza, y cierto con buenos sucesos; empero, las grandes virtudes del Canchalagua, según nos muestra la experiencia, son el purificar la sangre de todas malignas cualidades (...) (Montengero, 1945, p. 173, grifos nossos).

Mas, se na Materia Médica Misionera encontramos muitas evidências da influência que o meio e a experiência exerceram sobre seu autor, o mesmo não pode ser observado, ao menos com a mesma intensidade, no Libro de Cirugía. Nele, verifica-se que as experiências pessoais e o cotidiano da redução perdem espaço para informações mais técnicas sobre anatomia, para as descrições das enfermidades e da composição dos remédios e para os procedimentos cirúrgicos.

o tom tratadístico que assume o Libro de Cirugía deve-se, muito provavelmente, à operação compilatória de outros tratados realizada por seu autor. Observa-se, em razão disso, uma escrita mais impessoal, em que poucas são as experiências pessoais compartilhadas, como se pode constatar na passagem abaixo:

(...) y enseña Hipocrates que en los dias que se exacerban, o inquietan los morbos se terminan, si por pares em pares, si por en pares en nones por esto dijo Galeno, que rara vez acaecía crisis en el dia $4^{\circ}$ y que el solo observò una, más yo dice Trapiella, e observado tres, y las mortales (Libro de Cirugía, 1725, p. 381, grifos nossos).

As observações e experiências referidas pelo autor-compilador estão, em sua maioria, associadas àquelas realizadas por reconhecidas autoridades médicas, como observado 
acima. Esse recurso não é tão usual na Materia Médica, na medida em que Montenegro expõe as experiências que ele próprio realiza, como no caso da planta virreina, cujas virtudes foram verificadas a partir do uso pelos índios: ${ }^{41}$

Yo viendo y reconociendo la virtud tan eficáz para este efecto me he valido de ellas en varios pasmos rectos, ó totales, que son los que rectamente embarran todo el cuerpo por igual, dejandole inmoble, y tenso: con el cocimiento de sus ojas y flores, y juntamente con untura que hago apropiada para los espasmos en esta forma (...) (Montenegro, 1945, p. 322).

Dentre as experiências ou observações feitas pelo autor do Libro, está a receita que prevê a colocação de líquido de enxofre sobre as narinas ou a ingestão de três claras de ovos misturadas com uma pequena colher de sal, algo que, segundo ele, era “(...) mui husado en estas doctrinas (...)" para ajudar nas complicações durante o parto (Libro de Cirugía, 1725, p. 321-322, grifos nossos). ${ }^{42}$ Em outra passagem, o autor informa que " Estando yo en Sas Miguel me avisaron de la enfermedad de un Yndio que hera colica flatuosa, a la qual llaman ellos Yabirù" ${ }^{43}$ Para tratá-lo, preparou uma solução à base de líquido de unha de vaca, vinho e sal, com a qual conseguiu curar o índio (Libro de Cirugía, 1725, p. 269, grifos nossos). Em outra receita, indicada para dentes cariados, ele recomenda:

(...) se ha de cuidar no usar para lo dicho de cosas que se quiebren dentro de la llaga, para este fin dice Falope [Gabriel Falloppio] que no ay cosa mejor, que la medula de aquella planta que se llama Mijo negro al qual he visto en el Pueblo del Corpus (...) (Libro de Cirugía, 1725, p. 407, grifos nossos). ${ }^{44}$

E contra as temidas pestes, o autor-compilador aconselha a realização de purgas, sendo que “(...) Septalio, quien dice que en todas las Pestes que assistiò esperimentò felisisimos susesos purgando a los Pestiferos, $y$ lo mismo esperimentamos en la Peste que afligiò a estas Provincias los años de 718-19-20, y 21" (Libro de Cirugía, 1725, p. 364, grifos nossos)..$^{45}$

Os excertos acima destacados, além de nos auxiliarem na reconstituição do contexto e do espaço em que o Libro foi concebido e escrito, permitem algumas observações. Primeiramente, cabe chamar a atenção para a alta incidência de certas doenças, dentre as quais estavam a disenteria, as pedras nos rins, as febres e as intoxicações decorrentes de picadas de cobras. ${ }^{46}$ As enfermidades gastrointestinais e as verminoses eram, segundo o autor-compilador do Libro, provocadas

De ordinario (...) de llenarse el estómago de umores estraños glutinosos los quales sobre abundan de husar malos alimentos, o mal preparados como susede con los Yndios, o por opilacion del Ygado, o del vaso, o de las venas meseraycas, por lo qual quedando impuro el chilo o [ilegível] que hauia de atirar el igado se amontonan las flemas en el estómago causandolè grauesa, y excitaciones (Libro de Cirugía, 1725, pp. 276-277).

50 Já as epidemias de sarampo e varíola, como as que ocorreram na Província entre os anos de 1718 e 1730, além de terem afetado o ânimo dos nativos enfermos, provocaram a desestruturação das reduções, devido ao descenso demográfico. ${ }^{47} \mathrm{~A}$ orientação dada pelo autor nessas situações foi a de que "(...) es menester animarlos mucho a que coman, porque sus parientes no hacen sinó ponerles la comida o vebida delante, y no los animan a comer, ni a beber, y así muchos mueren de hambre, y sed" (Libro de Cirugía, 1725, p. 625). Na Materia Médica, além da indicação de uma correta alimentação, os indígenas enfermos deveriam, segundo Montenegro, receber tratamento adequado, como se pode constatar na recomendação da utilização do taperibá: ${ }^{8}$ 
Tomando de su raíz una onza y media de taperibá cocidas, y tomando vomito con ellas es único remedio en tiempo de pestecillas de viruelas, y sarampión, y de calenturas y cámaras, que provienen de corrupción del aire, ó de malos mantenimientos, ó por comer y beber malos mantenimientos (Montenegro, 1945, p. 164).

51 O envolvimento de milícias indígenas nos constantes conflitos militares da região platina parece justificar a escrita de uma obra que contemplasse descrições da anatomia do corpo humano e práticas médico-cirúrgicas, como o Libro de Cirugía.$^{49} \mathrm{Na}$ referência que faz ao bálsamo de aguaraybay, o autor destaca sua ação cicatrizante e menciona o cerco à Colônia de Sacramento: ${ }^{50}$

De esta manera sin claras de Guebo, aseite, Polbos, ni otro fomento, con solo este balsamo [aguaraybay], o extracto han sanado infinitos de eridas mui grandes, que con otras medicinas fueran mortales, y esto principalmente en las campañas, Guerras de los Ynfieles, y en las de los Portugueses en el cerco de la colonia [Sacramento], se hà esperimentado para heridas de balas fuego no serà tan bueno (Libro de Cirugía, 1725, pp. 429-430).

Do excerto acima depreende-se que o autor-compilador do Libro teve acesso a informações sobre procedimentos cirúrgicos realizados durante os conflitos ocorridos na Colônia de Sacramento. Na Materia Médica, apesar de não mencionar, especificamente, as batalhas nas quais esteve presente, Montenegro descreve os benefícios da raiz de Oruzús, ${ }^{51}$ indicado para ferimentos resultantes de lanças e balas, e destaca os experimentos que havia feito:

Esto tengo con más de cuatro hecho la experiencia, que atravesados el pecho de lanzas y balas, en las guerras que me hallé, que nadie pensaba que los tales pudiesen vivir 24 horas, por ser tales las heridas, que se les podía dar resuello, porque el viento venia por ellas, por mucho que se cosiesen y tapasen con bálsamos, y así mismo porque la sangre congelada, y engrumecida les tapaba la respiración, y para deshacer la tal congelación de la sangre, y comenzarla á corromper tomaba dos cucharas de yerba, y las ponía en agua fría, como cuatro onzas, batiéndola muy bien, y cuando veía que estaba bien infusa le ponía una cuchara no llena de sal molida, y encima agua caliente hasta llenar el mate, templándoselo para poderlo beber, y repitiendo este remedio hasta la tercera vez en las veinte y cuatro horas primeras deshacía los grumos, y soltaba la respiración, y al tercero día comenzaba á salir hecha materia con el lamedor: con la ayuda de nuestro Señor, que sea bendito por todo (Montenegro, 1945, p. 229).

53 Ainda que as experiências pessoais de cada autor tenham recebido um diferente destaque nas obras analisadas, elas exercem funções importantes. Se, na Materia Médica, elas servem para conferir legitimidade aos tratamentos indicados pelo autor, no Libro de Cirugía os registros dessa natureza não são tão frequentes, predominando os registros de experimentos realizados por outros indivíduos ou por autoridades reconhecidas da Medicina. Como pudemos observar, na primeira, existe um maior número de referências às reduções e aos indígenas que nela viviam e, ainda, menções aos saberes nativos observados e adotados pelo autor. Na segunda, por sua vez, as menções ao cotidiano reducional e aos procedimentos terapêuticos adotados pelos indígenas são raras, o que pode ser atribuído ao propósito da elaboração do Libro. O suposto autor do manuscrito deixa claro no Prólogo que ele pretendeu reunir, em um só livro, conhecimentos acadêmicos e práticos de Medicina, Farmácia e Cirurgia, que pudessem ser aplicados pelos encarregados das artes de curar nas reduções da Província Jesuítica do Paraguai. Não deve-se, no entanto, desconsiderar que a seleção das obras a serem compiladas e das indicações de tratamento divulgadas pelo autor-compilador no 
manuscrito não se constituam em manifestação de autoria daquele que o concebeu, escreveu, organizou e encadernou.

\section{Considerações finais}

54 O cotejo entre a Materia Médica Misionera e o Libro de Cirugía revelou semelhanças e diferenças entre as obras. Se a primeira pode ser definida como uma obra de botânica médica, a segunda se detém na anatomia do corpo humano e nas práticas médicocirúrgicas aplicáveis em certas enfermidades.

Enquanto o autor da Materia Médica revela com frequência, e com detalhes, experiências pessoais no exercício dos ofícios das artes de curar, o autor-compilador Libro de Cirugia está menos afeito ao compartilhamento das observações e experimentos por ele realizados. Esse aspecto fica evidenciado no grande número de autores e obras citados ao longo do manuscrito, constituindo-se em indicativo de que a compilação foi um recurso largamente e conscientemente utilizado pelo autor na elaboração do Libro de Cirugía.

56 Com relação ao contexto de produção dos dois manuscritos, a precária assistência médica na região da Província Jesuítica do Paraguai é apresentada como argumento para a escrita de ambas as obras. A reunião, em um só livro, de conhecimentos acadêmicos e práticos de Medicina, Farmácia e Cirurgia - foi, como se observa no Prólogo, o objetivo dos autores da Materia Médica e do Libro de Cirugía. Cenário comum às duas obras, o cotidiano das reduções é, no entanto, apresentado de forma diferente por seus autores. Se pode-se afirmar que o ambiente exerceu uma importância fundamental na escrita das obras, na medida em que a flora medicinal nativa é descrita e utilizada no tratamento de enfermidades, no Libro de Cirugía, diferentemente da Materia Medica, as informações sobre o ambiente em que se encontravam instaladas as reduções aparecem diluídas em meio às descrições da anatomia humana, das doenças e dos procedimentos cirúrgicos.

57 Contrapondo-se à visão consagrada pela historiografia, a análise que realizamos da Materia Médica Misioneira (1710) e do Libro de Cirugía (1725) não permite que afirmemos que o irmão jesuíta tenha sido o autor dos dois manuscritos, razão pela qual optamos por considerar o último como um manuscrito anônimo. Dentre as informações que devem ter, seguramente, contribuído para fundamentar a visão de historiadores como Garzón Maceda e Furlong estão as que mencionam a formação de Pedro Montenegro no Hospital Geral de Madrid - antes de seu ingresso na Companhia de Jesus - e sua atuação como boticário, enfermeiro e cirurgião nas reduções jesuíticas. Também o ano de 1725, que consta no frontispício do Libro, parece sustentar a possibilidade de que o irmão jesuíta poderia tê-lo escrito, pois faleceu somente em 1728.

58 A despeito desses plausíveis argumentos, a versão transcrita do manuscrito que analisamos parece, no entanto, reforçar a possibilidade de uma autoria coletiva, na medida em que constatamos a existência de vários tipos de letras, o que sugere a colaboração de outros autores-compiladores ${ }^{52} \mathrm{e}$, inclusive, de copistas indígenas..$^{53}$ Mas, se, por um lado, dificilmente conseguiremos desvendar as identidades dos autorescompiladores e copistas do manuscrito em questão, por outro, parece-nos evidente que enquanto "organizador[es] da disposição dos discursos", que "bordeja[m] os textos, recortando-os, delimitando-os" (Foucault, 2011, p. 59), esses indivíduos tinham a clara 
noção de que a atenção maior deveria ser dada ao seu potencial leitor, isto é, aquele que, tendo acesso ao Libro de Cirugía, quer fosse ele um enfermeiro ou um cirurgião, deveria ser bem orientado em relação aos procedimentos cirúrgicos e à mais eficiente “ administración de los remedios, que se deben aplicar" aos enfermos (Libro de Cirugía, 1725, p. 13).

\section{BIBLIOGRAPHY}

Acerbi Cremades, N. (1999). Los Jesuítas y la medicina de Córdoba desde 1599 a 1767. Actas Congreso Internacional Jesuitas 400 años en Córdoba, (pp. 11-26), Vol. 4. Córdoba.

Asúa, M. de (2014). Science in the Vanished Arcadia: knowledge of nature in the jesuit missions. Leiden: Brill.

Barros, J. D’A. (2007). História comparada - da contribuição de Marc Bloch à constituição de um moderno campo historiográfico. História Social ( 13), 7-21.

Barros, J. D’A. (2014). História Comparada. Petrópolis: Vozes.

Bloch, M. (1998a). Para uma história comparada das sociedades europeias. En M. Bloch, História e Historiadores: Textos reunidos por Étienne Bloch, (pp. 119-150). Lisboa: Teorema.

Bloch, M. (1998b). Comparação. En M. Bloch, História e Historiadores: Textos reunidos por Étienne Bloch, (pp. 113-118). Lisboa: Teorema.

Bonato, T. (2014). Viagem do olhar: relatos de viajantes e a construção do sertão brasileiro (1783-1822). Guarapuava: Unicentro.

Certeau, M. de. (2011). A Escrita da História. Rio de Janeiro: Forense Universitária.

Chartier, R. (1992). Textos, impressão, leituras. En L. Hunt (Ed.), A Nova História Cultural, (pp. 211-238). São Paulo: Martins Fontes.

Chartier, R. (1994). A Ordem dos Livros. Brasília: Editora UNB.

Compagnon, A. (2001). O demônio da teoria: literatura e senso comum. Belo Horizonte: Editora UFMG.

Corrêa, D. S. (2012). História ambiental e a paisagem. Historia Ambiental Latinoamericana y Caribeña - HALAC, III(1), 47-69.

Cosgrove, D. (1998). A Geografia Está em Toda Parte: Cultura e Simbolismo nas Paisagens Humanas. En Corrêa, R. L., Rosendhal, Z. (Eds.), Paisagem, Tempo e Cultura, (pp. 92-122). Rio de Janeiro: EdUERJ.

Cosgrove, D. (2002). Observando la naturaleza: el paisaje y el sentido europeo de la vista. Boletín de la Asociación de Geógrafos Españoles (34), 63-89.

Fleck, E. C. D. (2014a). Entre a caridade a e ciência: a prática missionária e científica da Companhia de Jesus (América platina, séculos XVII e XVIII). São Leopoldo: Oikos; Editora Unisinos.

Fleck, E. C. D., Rodrigues, L. F. M. e Martins, M. C. B. (2014). Enlaçar mundos: três jesuítas e suas trajetórias no Novo Mundo. São Leopoldo: Oikos; Editora Unisinos. 
Fleck, E. C. D. (2014b). "Moviome a escribir este libro, el deseo de reunir en un cuerpo, lo que no he podido hallaren libro alguno": reflexões sobre evidências de circulação e de apropriação de saberes e práticas científicas na obra Materia Medica Misionera de Pedro Montenegro (1710). En M. H. Alvim, (Ed.), Conhecimento, cultura e circulação de ideias na América Colonial Luso-hispânica, (pp. 21-50). Santo André: Universidade Federal do ABC.

Fleck, E. C. D. e Obermeier, F. (2018). O Libro de medicina, cirugía, e botica: um manuscrito anônimo de Matéria médica rioplatense da primeira metade do século XVIII. Antíteses, XI(21), 132-156.

Fleck, E. C. D. (2019). Evidências de circulação e apropriação de saberes farmacológicos e médicocirúrgicos em um manuscrito anônimo (América platina, século XVIII). Revista Eletrônica da ANPHLAC (26), 349-384.

Foucault, M. (2011). O que é um autor? En S. Queiroz, (Ed.), O que é um autor?, de Michel Foucault duas traduções para o português, (pp. 51-78). Belo Horizonte: FALE/UFMG.

Furlong, G. (1947). Médicos argentinos durante la dominación hispánica. Buenos Aires: Huarapes.

Garzón Maceda, F. (1916). La Medicina en Córdoba: apuntes para su historia. Buenos Aires: Talleres Gráficos Rodrígues Giles.

Illana Esteban, C. (2008). El cornezuelo del centeno (I): biología, historia y ergotismo. Boletín de la Sociedad Micológica de Madrid, vol. 32, 293-306.

Jackson, R. H. (2005). Crisis demográfica nas Misoes, 1730-1740. En C. A. Page, (Ed.), Educación y Evangelización. La experiencia de un mundo mejor. X Jornadas Internacionales sobre Misiones Jesuíticas, (pp. 129-136). Córdoba: Universidad Católica de Córdoba; Agencia Nacional de Promoción Científica y Tecnológica.

Kocka, J. (2014). Para além da comparação. Revista Esboços, XXI(31), 279-286.

Kristeva, J. (1974). Introdução à Semanálise. São Paulo: Editora Perspectiva.

Libro de Cirugía, 1725. (2014 [1725]). Colección Manuscritos. Archivo Histórico de la Província Franciscana de la Santíssima Virgen del Rio de la Plata. Buenos Aires: Ediciones Castañeda.

Maier, C. S. (1992-1993). La historia comparada. Studia Historica-Historia contemporánea, vol. X-XI, $11-32$.

Mancuso, L. (2005). A comparação no estudo da História da América Latina. Revista Projeto História, vol. 31, 259-275.

Martín Martín, C. y Valverde, J. L. (1995). La farmacia en la América colonial: el arte de preparar medicamientos. Granada: Universidad de Granada; Hermandad Farmacéutica Granadina.

Montenegro, P. (1945). Materia Médica Misionera. Buenos Aires: Imprenta de la Biblioteca Nacional. Perissinotto, R. (2012). Comparação e história na ciência social. En F. M. Heinz, (Ed.), Poder, instituições e elites: 7 ensaios de comparação e história, (pp. 13-32). São Leopoldo: Oikos.

Poletto, R. (2014). Uma trajetória por escrito: Pedro Montenegro SJ. e sua Materia medica missioneira. Dissertação inédita. Mestrado em História, Universidade do Vale do Rio dos Sinos (UNISINOS), São Leopoldo.

Quintana, R. (1945). Noticia preliminar. En P. Montenegro, Materia Médica Misionera, (pp. VXLVIII). Buenos Aires: Imprenta de la Biblioteca Nacional.

Scarpa, G. F., Anconatoni, L. M. (2019). La "Materia Médica Misionera" atribuida al jesuita Pedro de Montenegro en 1710: Identificación, sistematización e interpretación de los usos medicinales 
de las plantas y sus implicancias para la etnobotánica actual. IHS. Antiguos Jesuitas en Iberoamérica, VII (1), 27-46.

Schama, S. (1996). Paisagem e memória. São Paulo: Companhia das Letras.

Williams, R. (2011). o campo e a cidade: na história e na literatura. São Paulo: Companhia das Letras.

\section{NOTES}

1. Apesar da menção ao ano de 1725 no frontispício, acreditamos que a versão que analisamos nesse artigo tenha sofrido interferências nos anos seguintes, com a adição de outros manuscritos à versão original do Libro (Fleck, 2019).

2. Sobre a Materia Médica Misioneira, ver mais em: Furlong (1947), Martín Martín e Valverde (1995), Fleck (2014a; 2014b), Fleck; Rodrigues e Martins (2014) e Poletto (2014). Sobre o Libro de Cirugía, ver mais em: Garzón Maceda (1916), Furlong (1947), Asúa (2014), Fleck e Obermeier (2018) e Fleck (2019).

3. O historiador jesuíta Guillermo Furlong (1947, p. 74) afirmou que "Montenegro es el indiscutido autor de la tan zarandeada Materia Medica Misionera, pero, a nuestro parecer, es el igualmente el autor del 'Libro de Cirugía' que, en 1916, dio a conocer el doctor Félix Garzón Maceda en magna y eruditísima historia de la 'Medicina en Córdoba"

4. Para Garzón Maceda, o Libro de Cirugía "Es lo más completo que ha circulado y lo de mayor mérito que puede hallarse entre los códices médicos coloniales que han llegado hasta nosotros (...)" (Garzón Maceda apud Acerbi Cremades, 1999, p. 19).

5. Em 1704, Portugal e Espanha entraram em conflito, por motivos que envolviam a sucessão ao trono espanhol, o que veio a ter consequências nos conflitos entre as coroas ibéricas na região do Prata. Inicialmente, cogitou-se o envio de nove mil indígenas missioneiros para o ataque à Colônia, mas os Superiores das Missões do Uruguai e do Paraná não autorizaram sua liberação, temendo pela segurança das reduções. Acredita-se que tenham se deslocado em torno de quatro mil indígenas, provenientes de Corrientes, Córdoba e Tucumán.

6. A comparação, como método de investigação, tem a finalidade de formular e pensar questões, fazer analogias, perceber variações e identificar semelhanças e diferenças entre o mais conhecido e aquilo que é apresentado como novo (Barros, 2007, 2014; Bloch, 1998a, 1998b; Perissinotto, 2012). Ainda que o presente estudo parta de uma perspectiva comparativa, e não necessariamente de uma história comparada, os trabalhos de Maier (1992), Mancuso (2005) e Kocka (2014) trazem significativas contribuições sobre a comparação em História, além de análises historiográficas sobre o tema.

7. 0 conceito de intertextualidade foi desenvolvido, especialmente, por Julia Kristeva, em sua obra Introdução à Semanálise, de 1969. A ideia central do conceito é a noção dialógica que os textos mantêm entre si. Ou seja, trata-se da percepção de que um texto é construído a partir de seus antecessores, pois, como afirma Kristeva, “(...) todo texto se constrói como mosaico de citações, todo texto é absorção e transformação de um outro texto" (Kristeva, 1974, p. 64). Para Antoine Compagnon, essa dimensão dialógica marca a mudança de perspectiva nos estudos dos textos; se antes fechados em sua lógica interna, agora “(...) a intertextualidade se apresenta como uma maneira de abrir o texto, se não ao mundo, pelo menos aos livros, à biblioteca" (Compagnon, 2001, p. 111). Considerando-se a leitura uma prática “(...) que raramente deixa marcas (...)", conforme observou Roger Chartier (1994, p. 11), a intertextualidade apresenta-se, portanto, como vestígios de uma leitura pregressa.

8. Observando que o viés comparativo aqui adotado, como alerta Renato Perissinotto (2012, p. 19), “(...) pressupõe certo grau de semelhança e de diferença entre as coisas comparadas (...)" evitando-se, assim, o equívoco de cotejar coisas rigorosamente iguais entre si, ou mesmo, 
radicalmente diferentes, destacamos que ambas as obras estão inseridas em um contexto de produção - espacial e temporal - semelhante, o que não elimina as diferenças entre as obras, como destacaremos adiante.

9. Materia Médica Misionera está estruturada em cinco capítulos, além do Prólogo, sendo que os três primeiros são dedicados às nomenclaturas e propriedades das plantas, às instruções sobre a colheita e as suas virtudes. Acredita-se que Montenegro não seja o autor do quinto e último capítulo, que versa sobre "Otras curiosidades e recetas útiles" (Fleck, 2014a).

10. Datado de 1725 , o Libro de Cirugía apresenta uma estrutura organizada em nove capítulos, além do Prólogo e de tabelas com informações geográficas das reduções da Província Jesuítica do Paraguai. O primeiro capítulo intitula-se "Dispensário Médico, conteniendo diferentes fórmulas magistrales de medicamentos, para ser administrados por via oral o em aplicaciones externas", o segundo "Anatomía del cuerpo humano", o terceiro "Tratado Brebe del Modo de Sangrar", o quarto "Enfermedades de la cabeza", o quinto "Enfermedades del Pecho", o sexto "Enfermedades de la Cavidad Abdominal", o sétimo "Enfermedades de las mujeres", o oitavo "Tratado de las fiebres" e o último "Capítulo del pulso, orina y crisis. Algunos tratamientos quirúrgicos; medidas para curar el 'morbo gálico' y el Escorbuto". Anexado a essa primeira parte, encontra-se o manuscrito denominado "Libro $2^{\circ}$ de Cirugía, de los tumores en general", que conta como um "Tratado de los Pronósticos con tablas que muestran la complexión y aspecto de los siete planetas y los doce signos celestes, entre los cuales está la luna y los días más convenientes para evacuar los humores, por medio de las sangrías o purgantes" (Fleck, 2019).

11. O Palo Santo, cujo nome científico é Bursera graveolensi, é uma árvore nativa das florestas da América do Sul, da qual é extraído um óleo essencial e são fabricados incensos. Utilizado pelos nativos americanos e apropriado pelos europeus, apresenta virtudes depurativas, antirreumáticas, antissépticas e antifúngicas.

12. A ideia de que o autor do Libro de Cirugía é também um compilador foi apresentada por Eliane Fleck e Franz Obermeier (2018). Para os autores, pode-se, com base na análise do manuscrito “(...) formular a hipótese de que as partes intituladas Tratados sejam transcrições na íntegra de obras de referência já publicadas, e que as partes intituladas Enfermidades sejam autorais, conciliando passagens extraídas de outros autores com experiências realizadas pelo autor-compilador" (Fleck e Obermeier, 2018, p. 135).

13. O mechoacan ou uva da América - Phytolacca americana - é uma planta tóxica natural da América do Norte, que foi introduzida em outras regiões, sendo muito utilizada como vomitivo e no tratamento da sífilis.

14. Cabe destacar que enquanto a Materia Médica Misionera explora, por excelência, as propriedades medicinais das plantas, o Libro de Cirugía apresenta uma quantidade muito significativa de compostos químicos nas receitas indicadas. Essa constatação, possivelmente, decorra das diferenças já citadas entre as obras. Contudo, é de se observar que tais soluções químicas, como o chumbo e o mercúrio, já de longa data, faziam parte das boticas da América platina, como o próprio inventário da botica de Córdoba, de 1772 (Fleck, 2014a), indica apesar da distância temporal que o separa do Libro de Cirugía.

15. A cópia manuscrita do tratado Materia Médica Misionera, com data de 1790, que se encontra no Instituto Anchietano de Pesquisas - Unisinos, parece confirmar a circulação de cópias de obras desta natureza entre os diferentes espaços de atuação da Companhia de Jesus. Estudos já têm demonstrado que muitas das obras que integravam as bibliotecas das boticas ou colégios da Companhia foram copiadas por indígenas, que, desta forma, contribuíram para a conformação de uma "rede de troca de experiências e de informações" e para a disseminação de uma série de saberes e práticas de cura. Ao compararmos a versão de 1790 com a de 1710 , percebemos que a primeira não conta com alguns dos elementos pré-textuais presentes na versão original da obra, tais como as tablas. O fato de a versão do final do século XVIII não ter considerado a versão 
integral do manuscrito pode estar associado a certo pragmatismo ou a uma seleção - arbitrária ou não - do seu conteúdo quando da realização da cópia.

16. Conhecida também como urgebão ou erva-de-ferro, à verbena (Verbena officinalis L.) são atribuídas propriedades relaxantes, calmantes, sudoríficas e diuréticas. É usualmente cultivada na Europa e na América do Sul.

17. Ao longo do Libro de Cirugía, seu autor refere-se à doença "fuego de San Anton", nome popular dado à doença hoje conhecida como ergotismo. Trata-se de uma enfermidade causada pelo fungo esporão-do-centeio (Claviceps purpurea), cuja biossíntese de alcaloides provenientes da ergolina afeta o sistema nervoso central e contrai os vasos sanguíneos, podendo causar gangrena nos membros superiores e inferiores, convulsões e até levar a morte (Illana Esteban, 2008). As primeiras epidemias de ergotismo ocorreram na Idade Média, acometendo, especialmente, as camadas mais pobres das cidades, consumidoras de cervejas, vinhos, queijos e pães contaminados pelo fungo. $O$ nome da doença se difundiu devido à sensação de queimação dos membros afetados e pala ação dos Irmãos Hospitalários de Santo Antônio, congregação católica criada para amparar os enfermos, em 1095 (Illana Esteban, 2008). Somente em meados do século XVII é que o ergotismo foi associado ao fungo presente nos cereais.

18. Opção comum no paisagismo, a canfístula (Peltophorum dubium), ou angico-amarelo, chuva de ouro e cássia imperial, é destacada por suas propriedades cicatrizantes e purgativas.

19. Bledo menor, beldros ou bredos são alguns dos nomes populares da planta Amaranthus retroflexus. Originária da América do norte é facilmente localizada em regiões quentes do globo. Dentre suas virtudes medicinais está o tratamento da rouquidão e da disenteria. Acetosa mayor, consuelda mayor, confrei ou orelha de asno, são os nomes comuns da planta ymphytum officinale L. Dentre suas virtudes medicinais destacam-se a ação cicatrizante, distúrbios gastrointestinais e como emplasto é destacada na recuperação de queimaduras e de fraturas. O poejo (poleo - Mentha pulegium) é uma espécie muito utilizada devido a sua ação expectorante e calmante. O hissopo (Hyssopus officinalis) é uma planta nativa da Europa e do Oriente Médio, sendo utilizada medicinalmente devido à sua ação expectorante e antisséptica. Nativa da Ásia Ocidental e Central, a ajedrea (Satureja hortensis L.), popularmente conhecida como segurelha-anual, segurelha-das-hortas ou segurelha-dos-jardins, é uma planta com propriedades adstringentes e antissépticas, indicada no tratamento de parasitas intestinais. Arrayán ou arrayán palo colorado (Luma apiculata), é uma árvore da região dos Andes chilenos. A infusão de sua casca é indicada no tratamento de hemorragias e de feridas internas, devido a sua propriedade adstringente. Por fim, a goiabeira (Psidium guajava) é uma árvore nativa da América Tropical, e a infusão de suas folhas é indicada no tratamento da disenteria e de inflamações da boca e da garganta.

20. A existência de pontos em comum entre as obras analisadas é pouco reveladora de sua autoria. Conforme Fleck e Obermeier (2018), a intensa circulação de manuscritos de medicina e farmácia entre as reduções platinas e as cópias e compilações destas obras realizadas por diversos sujeitos, que atendiam a interesses práticos específicos, tornaram generalizado o conhecimento de determinadas plantas e receitas na região.

21. Conforme as reflexões de Michel de Certeau (2011), o discurso apresenta uma natureza performativa devido à intrínseca tensão entre a verificabilidade e a credibilidade. Nesse sentido, aquilo que não é rigorosamente verificável deve ser compensado pela inserção de elementos que reforcem a fidedignidade do discurso. Um deles é a citação, aquilo que conecta o texto com o saber do outro, de modo que, citar o nome do outro traz consigo crédito (Certeau, 2011). Segundo o próprio autor: “(...) a linguagem citada tem por função comprovar o discurso: como referencial, introduz nele um efeito de real; e por seu esgotamento remete, discretamente, a um lugar de autoridade. Sob esse aspecto, a estrutura desdobrada do discurso funciona à maneira de uma 
maquinaria que extrai da citação uma verossimilhança do relato e uma validade do saber. Ela produz credibilidade" (Certeau, 2011, p. 101).

22. Dentre os autores mais citados por obra, estão: na Materia Médica, encontramos Pedânio Dioscórides (35 menções), Andrés Fernández Laguna (32), Pedro Andrés Mathiolo Senense (31) e Plinio (15); no Libro de Cirugía, encontramos Juan Vigier (85 menções), Cláudio Galeno (50), Andrés Fernández Laguna (39), Felipe Borbon (37), Domingo Trapiella y Montemayor (22), Pedro Francisco Castellón (22), Jerónimo Soriano (21), Pedânio Dioscórides (21), Diego Antonio de Robledo (20), Hipócrates (20), Pedro Andrés Mathiolo Senense (16), Manuel de Porras (12), Bernardo de Gordônio (12) e Augustin Farfán (10).

23. No cotejo que realizamos, constatamos que vinte e quatro autores citados na Materia Médica não foram mencionados no Libro de Cirugía. Cabe, no entanto, observar que estes autores tiveram menos de dez menções na obra atribuída ao irmão jesuíta Montenegro.

24. Conforme Quintana (1945, p. XXX), “Los 136 dibujos de plantas que lo [o manuscrito] embellecen no son en su mayoría originales y están tomados de las obras de Pisón, especialmente de la comentada por Bonti, De Indiae utriusque re naturali el médica, como el mismo Montenegro lo revela, cuando dice haberlas consultado comprobando que trahen varias plantas con los nombres de estas tierras, de las cuales he traducido, y trasladado algunas, las que reconozco de mayores virtudes (...)'."

25. Manuel de Porres (século XVII - século XVII) foi um cirurgião que atuou no Hospital Geral de Madri e no de Pasión, alcançando o posto de cirurgião pessoal do rei Felipe V. É autor das obras Medula de Cirurgia y Examen de Cirujanos (1691) e Anatomía Galénico-Moderna (1716). As passagens inseridas no Libro de Cirugía pelo autor-compilador foram extraídas da obra Medula de Cirurgia y Examen de Cirujanos.

26. Diego Perez de Bustos (?-1633) atuou como sangrador real a serviço do rei espanhol Felipe IV. Foi também autor da obra Tratado Breve de Flebotomía, de 1630, que teve uma segunda publicação em 1709.

27. Nessa passagem, encontramos uma informação atribuída ao médico suíço Felix Platero, relatada pelo boticário francês Juan Vigier.

28. Em análise feita do prólogo do Libro de Cirugía, Eliane Fleck e Franz Obermeier (2018) destacaram as raras menções feitas a médicos da América Latina pelo autor-compilador, se comparadas ao número de autores europeus citados. Dentre os autores mencionados, o estudo identificou que quatro deles se encontravam nos catálogos das bibliotecas dos colégios jesuíticos de Córdoba e de Assunção, o que parece apontar para a possibilidade da consulta a essas obras pelo próprio autor-compilador do Libro de Cirugía (Fleck e Obermeier, 2018).

29. Trata-se do Irmão Heinrich Peschke, boticário boêmio que trabalhou em Córdoba. Em outra passagem, ao comentar sobre as febres, o autor-compilador afirma que: "Por ultimo describirè aqui un remedio admirable para curar las tercianas, y otras fiebres periodales, el qual me comunicò el Hermano Enrique Pesque como secreto especial, y que a el se lo declarò un Español en Cadiz, quien hauia hecho tantas curas con este remedio que por eso se hallaua con dignidad grande: la receta es como se sigue" (Libro de Cirugía, 1725, p. 349).

30. Yerba de la víbora (Asclepias mellodora) é uma planta tóxica nativa da América do Sul.

31. Rosa de Alexandria (Paeonia broteri) é uma planta nativa da Península Ibérica utilizada para fins medicinais desde a Antiguidade, por sua indicação no tratamento de inflamações e da febre. Já a rosa de mosqueta (Rosa moschata) é originária da Ásia e possui propriedades antioxidantes e cicatrizantes.

32. Berdolaga ou beldroega (Portulaca oleracea) é uma planta originária da Ásia e que, atualmente, pode ser encontrada em todos os continentes. Apreciada na culinária, a Portulaca oleracea também apresenta virtudes medicinais, sendo indicada no tratamento de doenças hepáticas e renais por sua ação diurética. 
33. Nessa passagem, o autor faz referência à água preparada com vitriolo romano, que, na verdade, é o ácido sulfúrico, indicado em tratamentos desde a Antiguidade, por autores como Dioscórides e Plínio.

34. A antiga Província Jesuítica do Paraguai abrangia diversas ecorregiões, tais como, a do Chaco Seco, do Monte de Sierras e Bolsones e de Espinal, caracterizadas pelo clima árido e pelo baixo volume de precipitação; as Selvas de las Yungas e a Selva Misionera ou Paranaense, em que se observa um maior índice pluviométrico, favorecendo a diversidade da flora e da fauna; os Esteros del Ibera, próximo ao Chaco úmido, região com condições favoráveis a inundações e as ecorregiões de Monte de Llanuras y Mesetas e da Estepa Patagonica, em que se verifica um ambiente inóspito.

35. $O$ conceito de paisagem aqui utilizado não se refere apenas às cenas captadas pelo olhar $\mathrm{e}$ vertidas para o registro textual. Trata-se, sim, da descrição dos elementos naturais e artificiais mediados pela sensibilidade do observador-autor -, e, ainda, das relações que os sujeitos estabelecem com o seu entorno natural. (Bonato, 2014; Corrêa, 2012; Cosgrove, 1998; 2002; Schama, 1996; Williams, 2011).

36. O altocigo, lentisco, aroeira ou alfostigueiro (Pistacia lentiscus) é uma planta nativa do Mediterrâneo e apreciado por sua resina aromática.

37. No período colonial, a Província Jesuítica do Paraguai abrangia a vasta região que se caracterizava por uma cobertura vegetal muito diversificada, na qual conviviam a savana, com arbustos esparsos e de porte médio e o predomínio da alternância climática entre estações de chuva e de secas; a pradaria, com vegetação rasteira e clima úmido, e a floresta tropical, com árvores de grande porte em menor densidade.

38. Cabe destacar que o sistema de classificação das espécies do botânico sueco Carlos Lineu (1707-1778), que revolucionou os estudos de História Natural, somente foi publicado na obra Systema Naturae, em 1735. Até então havia outros sistemas de classificação científica das espécies, como o do botânico francês Tournefort (1656-1708), exposto na sua obra Éléments de botaniques, de 1694. Tournefort inovou ao difundir o conceito de gênero e ao hierarquizar a classificação em classes, secções, gêneros e espécies. Ainda assim, a descrição das plantas na Materia Médica Misioneira não adotou nenhum padrão científico de classificação.

39. Erva santa (Eriodictyon californicum) é uma planta nativa da América do Norte, cujas propriedades medicinais são indicadas no tratamento de enfermidades respiratórias, como asma e rinite.

40. A canchalágua (Sisyrinchium micranthum Cav.) é uma planta nativa da América do Sul e apresenta propriedades diuréticas, anti-inflamatórias e depurativas.

41. Conhecida como virreina, tagetes ou cravo-de-defunto (Tagetes patula), a planta possuiu propriedades anti-inflamatórias, anti-sépticas e cicatrizantes.

42. As claras de ovos são mencionadas em receitas tanto da Materia Médica Misioneira, quanto do Libro de Cirugía. No primeiro, as claras são usadas em uma receita contra febres intensas, a qual, segundo Monetenegro, “(...) yo he usado de ella en esta forma: Siempre viva una onza, rosa seca, y cebada quebrantada de cada uno onza y media, ojas de guabiyú negro el menor una onza, todo muy cocido en azumbre y medio de agua, cuese hasta mermar más de la mitad, de este cocimiento se bá sacando á medio cuartillo para labativas, y con un huevo con un poco de azucar se echan labativas cuatro cada dia" (Montenegro, 1945, p. 156). Já no Libro de Cirugía ela é utilizada na água de alume, sendo esta “(...) muy buena para curar las llagas de las partes secretas. Hazese de esta manera: batese una onza piedra alumbre con 4 claras de huevos, hasta que se disuelva más de la mitad del alumbre: cuelase el licor para usarle, porque deseca los excrementos, conforta la parte, y hinche de carne la ulcera. Todas las aguas, o cocimientos de alumbre aplicados resuelven las hinchazones edemativas." (Libro de Cirugía, 1725, p. 537). Utilizadas em unguentos e xaropes nas obras analisadas, as claras de ovos apresentam uma 
grande quantidade de proteínas de origem animal, sendo eficazes na recuperação de tecidos, especialmente, o muscular.

43. É plausível supor que o emprego das denominações de plantas e animais nas línguas nativas no Libro visasse tanto a facilidade de sua localização pelos indígenas das reduções, quanto sua correta utilização nas receitas indicadas nos tratamentos de enfermidades e nos procedimentos cirúrgicos.

44. Gabriel Falloppio (1523-1562), anatomista e cirurgião italiano, autor das obras Observationes anatomicae (1561) e Opera omnia (1584).

45. Ludovico Settala, ou Septalio (1552-1633), professor na Universidade de Pádua e comentarista da obra de Hipócrates. Dentre suas obras destaca-se Labyrinthi medici extricati, publicado em 1687.

46. A ocorrência destas enfermidades no ambiente das reduções não é apenas identificável na leitura do Libro de Cirugía. A Materia Médica também revela a preocupação com estas doenças, o que sugere a quantidade de ervas indicadas e de receitas descritas no tratamento contra a disenteria, as pedras nos rins, as verminoses, as febres e as picadas de animais peçonhentos. Um exemplo disso é a referência que Montenegro faz ao Palo Santo, conhecido dos índios Guaicurus e Mocobies, que era “(...) uno de los más eficaces remedios que hasta hoy se han descubierto en curar úlceras, y llagas de todas las partes internas: como son del pulmon, del higado, estomago, intestinos, riñones y vejiga (...)" (Montenegro, 1945, p. 278).

47. Recomendamos ver o estudo de Robert Jackson (2005) sobre o impacto das epidemias de sarampo e de varíola na Província Jesuítica do Paraguai nas primeiras 3 décadas do século XVIII.

48. Taperibá (Eupatorium perfoliatum), também conhecida como erva-de-cobra e plantasudorípara. Devido às suas propriedades diaforéticas e laxantes foi utilizada no tratamento de gripes e pneumonias.

49. Considerando os conhecimentos médicos e prático-cirúrgicos demandados em conflitos militares à época, tais como estancar hemorragias, cauterizar ferimentos profundos, extrair projéteis e estilhaços e realizar amputações de membros comprometidos, poder contar com um manual de anatomia e de instruções médico-cirúrgicas seria fundamental para o reestabelecimento das condições dos soldados alvejados.

50. Aguaraybay ou aroeira-salso (Schinus molle - Anacardiaceae) é uma árvore nativa da América do Sul, e seu bálsamo possui propriedades purgantes, cicatrizantes, além de ser indicado no tratamento de doenças estomacais e renais.

51. Oruzú, em espanhol, ou regaliz e alcaçuz em português, são alguns dos nomes comuns da planta (Glycyrrhiza glabra L.). Utilizada em confeitos e na preparação de medicamentos, a planta possui propriedades anti-inflamatórias, antiespasmódicas, expectorantes, antissépticas, diuréticas e laxantes.

52. Esta afirmação decorre da menção feita ao ano de 1736 (onze anos depois da data que consta no frontispício do Libro) que encontramos na p. 55 da segunda parte do manuscrito, escrita em uma letra um pouco mais livre do que a empregada na primeira parte do manuscrito.

53. A semelhança entre a letra do Prólogo e da primeira parte da obra nos leva a acreditar que elas tenham sido redigidas pela mesma pessoa, diferentemente da segunda parte ("Libro $2^{\circ}$ de Cirugía, de los tumores en general"), cuja letra se diferencia da anterior (Fleck e Obermeier, 2018). 


\section{ABSTRACTS}

This article presents and analyses two manuscripts of medicine and pharmacy from the beginning of the 18th century, Materia Médica Misioneira (1710) and the Libro de Cirugía (1725), which have their authorship attributed to Jesuit Pedro Montenegro. Beyond the discussion about the appropriation of classical knowledge about Medicine and Pharmacy from native knowledge, their structures and narrative styles are compared in order to support the questioning of the same authorship attributed to both manuscripts. Distancing from the vision consecrated by historiography, we propose that the Libro de Cirugía was composed in different moments and had the collaboration of several authors-compilers, including indigenous copywriters.

Neste artigo, apresentamos e analisamos dois manuscritos de medicina e farmácia do início do século XVIII, a Materia Médica Misioneira (1710) e o Libro de Cirugía (1725), que têm sua autoria atribuída ao irmão jesuíta Pedro Montenegro. Além da discussão dos indícios de apropriação de conhecimentos clássicos de Medicina e Farmácia e de saberes nativos, cotejamos suas estruturas e estilos narrativos, a fim de subsidiar o questionamento da mesma autoria atribuída aos dois manuscritos. Distanciando-nos da visão consagrada pela historiografia, propomos que o Libro de Cirugía foi composto em momentos distintos e contou com a colaboração de vários autorescompiladores, inclusive, de copistas indígenas.

En este artículo, presentamos y analizamos dos manuscritos de medicina y farmacia de principios del siglo XVIII, la Materia Médica Misionera (1710) y el Libro de Cirugía (1725), que tienen su autoría atribuida al hermano jesuita Pedro Montenegro. Además de la discusión de los indicios de apropiación de conocimientos clásicos de Medicina y Farmacia y de saberes nativos, cotejamos sus estructuras y estilos narrativos, con el fin de apoyar el cuestionamiento de la misma autoría atribuida a los dos manuscritos. Distanciándonos de la visión consagrada por la historiografía, proponemos que el Libro de Cirugía fue compuesto en diferentes momentos y contó con la colaboración de varios autores-compiladores, inclusive, de copistas indígenas.

INDEX

Palabras claves: Materia Médica Misionera, Libro de Cirugía, manuscritos de medicina y farmacia, América del sur, Siglo XVIII

Palavras-chave: Materia Médica Misionera, Libro de Cirugía, manuscritos de medicina e farmácia, América platina, Século XVIII

Keywords: Materia Médica Misionera, Libro de Cirugía, manuscripts of medicine and pharmacy, Platin America, 18th century

\section{AUTHORS}

\section{ELIANE CRISTINA DECKMANN FLECK}

Universidade do Vale do Rio dos Sinos, Brasil

Correio eletrônico: ecdfleck@terra.com.br

\section{MAICO BIEHL}

Universidade do Vale do Rio dos Sinos, Brasil 
Correio eletrônico: maicobiehl@yahoo.com.br 